\title{
CHERCHELL: AN ALGERIAN MEDITERRANEAN HISTORICAL CITY WITH A RICH ISLAMIC HERITAGE HOUSING
}

Abdel Kader Behiri

Naima Chabbi-Chemrouk
Institut d'Architecture et d'Urbanisme, Université Saad Dahleb, Soumaa, Blida, Algeria

Ecole Polytechnique d'architecture et d'urbanisme, EPAU, Laboratoire architccture et Environnement, LAE, Algiers, Algeria

abdelkaderch@gmail.com

Ecole Polytechnique d'architecture et d'urbanisme, EPAU, Laboratoire architccture et Environnement, LAE, Algiers, Algeria

naima.chemrouk@gmail.com

Received: March 30 2015 ; Accepted: May 25 ${ }^{\text {th }} 2015$; Available Online: June $15^{\text {th }} 2015$

\begin{abstract}
Islamic residential architecture has some common architectural and architectonic elements issued from shared values such as privacy, simplicity and sobriety. Applied to residential architecture, these values led to some characteristic spaces and architectural elements such as patios or arcs. However, the Islamic civilisation is composed by different cultures spread on a great geographical area; this variety induced different interpretations of these elements by using different building shapes or materials. In this paper, we will present an example of this interpretation in the historical coastal city of Cherchell in northern Algeria. The city of Cherchell is a historic coastal city that witnessed the passage of several civilizations before the arrival of the Islamic one since its founding more than 2500 years ago. This specific situation as historical coastal city allowed the exchange with different civilizations around the Mediterranean Sea, giving rise in the Islamic period to a typical earth architecture characterised by a specific arch's typology. The objective of this article is to present an interpretation of Islamic heritage housing architecture in a Mediterranean historical coastal city (through two specific elements: building material and architectonic element). The long term aim of this study is the dissemination of traditional technics and know-how in order restore cultural heritage buildings and construct new projects with a strong Islamic identity.
\end{abstract}

Keywords: residential architecture; heritage; rammed earth; mediterranean historical cities; sustainable build ings

\section{Introduction}

Traditional residential architecture in Cherchell is the result of a historical stratification of the built frame and an accumulated know-how over the time, locally and through migration and cultural exchanges around the Mediterranean.

The combination of these factors generated technical and architectural special features that we approached through a historical study to understand the conditions of emergence and evolution of this architecture and through on-site surveys to identify the specific characteristics of these buildings.

In addition to the general characteristics of Islamic traditional housing, we studied (and will present) two characteristics in Cherchells' heritage housing:
- The material used is made of earth through the contextualized use of the technique of rammed earth. The earth is certainly one of the oldest construction materials; it was used since the first human buildings. The old civilizations of Persia, Assyria, Egypt, and Babylon used it widely, and many examples that reach us show that the earth was used to build both monumental, sacred works and residential buildings.

This material is still prominent nowadays in Africa, Middle East and South America. It is used within many implementation technics such as the cob, adobe, uncooked earth bricks, the rammed earth.

These building technics were shared all around the Mediterranean Sea and different civilizations used the earth as building 
material with almost the same manner, introducing, according to their needs and cultural exchanges, some cultural and regional specifications. These modifications give to each region a specific architecture language and a specific landscape.

- The architectural language of Cherchell's heritage housing architecture with a specific arc shape. Domestic architecture in the city of Cherchell is an austere architecture, the only decorative element that exists at the front is the arch in different variants: semi-circular, overruled, broken or a specific arcade with a geometric shape in basket handle that ends with a triangular accolade, which we called Cherchell's arch (this arch could be seen by profanes as a common one, but its geometric shape and construction method are original, as we will present later).

We will identify, first, the context of emergence of this architecture, its natural and urban environment, we will then present the layout of this architecture (different types of courtyard houses) and we will finally, study the specific elements previously cited.

\section{Cherchell's Geographical Situation}

Cherchell is a small harbour city located 100 $\mathrm{km}$ on the Mediterranean west coast of Algiers. The city scape is very unique as it lays between the sea and down the hills. The climate is mild and refreshed in summer by the sea breeze.

Cherchell is crossed from east to west by the RN 11 (national road), which connects the entire coastline of the Wilaya (department), which gave it a linear urban configuration.

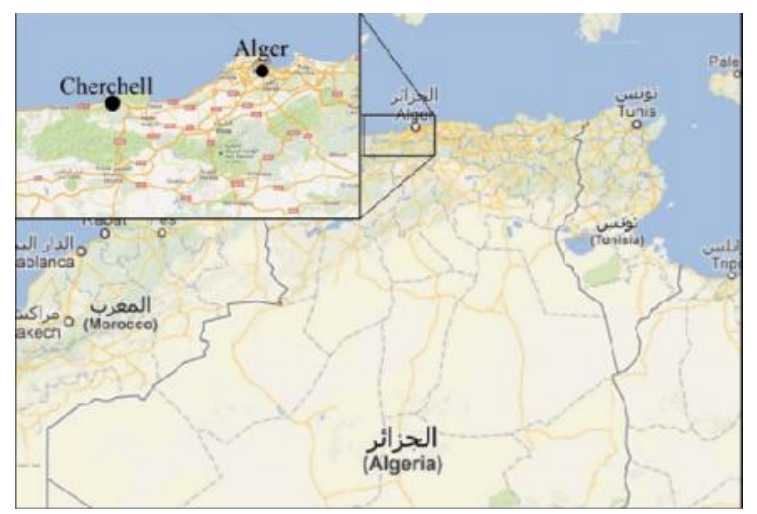

Figure 1. Geographical situation of Cherchell

\section{Historical Background}

Over two millennia history, the ancient Caesarea is a rich historical coastal city with heritage resources. Cherchell has its history going back to the 5th century B.C. when the Phoenician populated it and named it IOL capital of a Berber kingdom. Then, Juba II, who was appointed by Augustus King of Mauretania, sets IOL as the capital of his government and named it Caesarea. The city had an urban classic grid pattern. However, one district of the city did not fit in this scheme; it is probably inherited from a plot of the old IOL and followed the direction of the path leading from the ridge to the sea [1]. The used construction materials in that time were stones, cooked earth bricks and uncooked earth concrete.

In 1300, Muslims took control of it and was named Cherchell. The history of Cherchell during the islamic era could be divided into two distinct periods:

- A period of crisis and stratum that lasted until the end of the 15th century.

- A second one of a relative renaissance that coincided with the arrival of Andalusians and Ottomans in the 16th century [1], it is during this period that the rammed earth architecture was introduced to Cherchell. The Andalousian families coming from Granada and its surrounding area brought with them new construction technics to the city. These technics combined to local construction methods and the reuse of the older buildings materials, gave a new building approach and a new architectural language.

After that, the French colonized Cherchell in 1840. During this period, the north area became the new European district structured along the national road separating it from the medieval district. The French colons used a different building process, using the free stones they recover from roman archaeological sites. Since this period, the rammed earth became less used in Cherchell's buildings.

The old Medina has been neglected in favour of the new colonial district, and the result was that the old city lost its importance by losing its main purpose (centre of command and life). Historic districts that survived the various realignment actions have become an isolated core and juxtaposed to the new district.

Nowadays, the architectural and urban heritage of the city of Cherchell is concentrated at the historic centre and composed by three types of frames belonging to three distinct periods of history [1] (see fig. 2):

- Heritage dating back to antic period (archaeological heritage),

- Heritage dating from the Arab-Muslim era in the south of the city (it is in this old district that remain, today, the most Islamic heritage houses), 
- $\quad$ Finally the colonial heritage in the north.

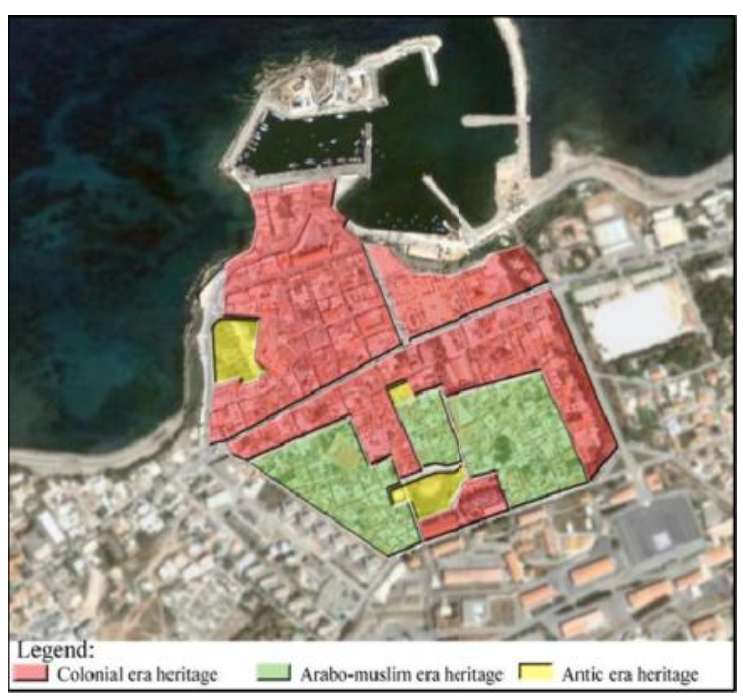

Figure 2. Architectural heritage in Cherchell historic centre (Source: Behiri, 2010)

\section{The Islamic Heritage Houses in Cherchell: Specificity and Architectural Language}

The most Islamic heritage housing constructions in Cherchell would have appeared in the early 16th century at the arrival of Andalusian immigrants and were used until the French colonization in the 19th century [2]. Today much of the built heritage dating from the Arab-Muslim era consists of houses built of "Pisé", in different varieties.

We will begin by presenting the characteristics of Cherchell's residential buildings, and then we will present the rammed earth technic used in these building and their architectural language:

A systematic survey of the housing stock in Cherchell's historical centre showed that like many courtyard houses around the Mediterranean, Cherchell's traditional house is a small, medium or large building, organized around the patio "Wast AlDar" (a courtyard in the centre of the house). For this house type, there are four variations in the spatial configuration: houses in ground level with or without peristyle and houses having first floor with or without peristyle.

\section{Ground Level Houses Without Peristyle}

This type of house has no galleries. The rooms overlook the' "Wast Al-Dar". These are dwellings with relatively medium size, generally, three bedrooms arranged in a helix shape that occupy three sides. Kitchen and bathroom with "Skifa" (the entrance) occupy the fourth side.
The openings of these houses are small and usually use the wooden lintel, except for some ones with arches inside; in this case, the same type of arch is used on the front door.

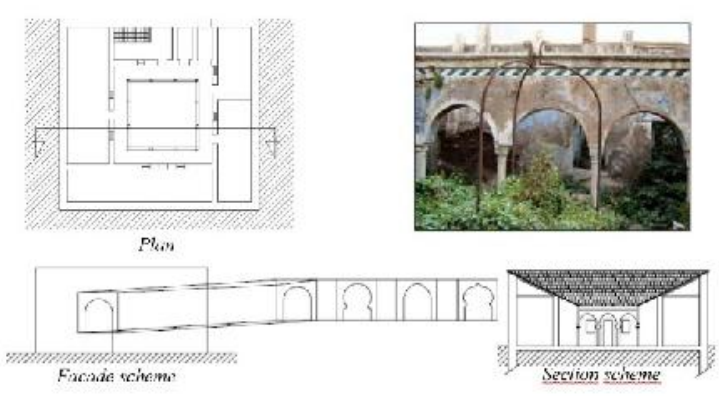

Figure 3. Example of Ground level houses with peristyle (Source: Behiri, 2007)

\section{Ground Level Houses with Peristyle}

These houses are larger than previous ones. They generally have four galleries that overlook the central patio most often headed with semi-circular, broken, or horseshoe arches. Sometimes there is the presence of one single gallery overlooking the main room.

The distribution of space is the same as for the type above, with bigger surfaces, larger patio and finer decorations (ceramics, arches). The scheme of the front of this house type is identical to the previous one

\section{Houses Having First Floor Without Peristyle}

These are houses of the first pattern with a small footprint, which has an evolution in height to recover lost ground space. The first floor usually occupies one side and has a large bedroom and two average ones. A terrace occupy the residual space of the floor. Stairs leading to upper stage are uncovered. The gallery on the first floor is cantilevered overhang or on the floor of the lower space.

The openings of these houses use either wooden lintels, either semi-circle arches, broken arches or basket handle arches with accolade.

Their entrance is either on the free side of "wast al- dar" if it overlooks the street or in the same way as the first pattern houses. If the terrace is on the street side, the wall is higher, so that the person standing behind it is not visible from the street.

The front of this house type is the result of height duplication of the previous type, sometimes the upper level has windows on the outside (figure 4). These openings are generally rectangular, but 
sometimes we can find windows with same arch as the door ones.

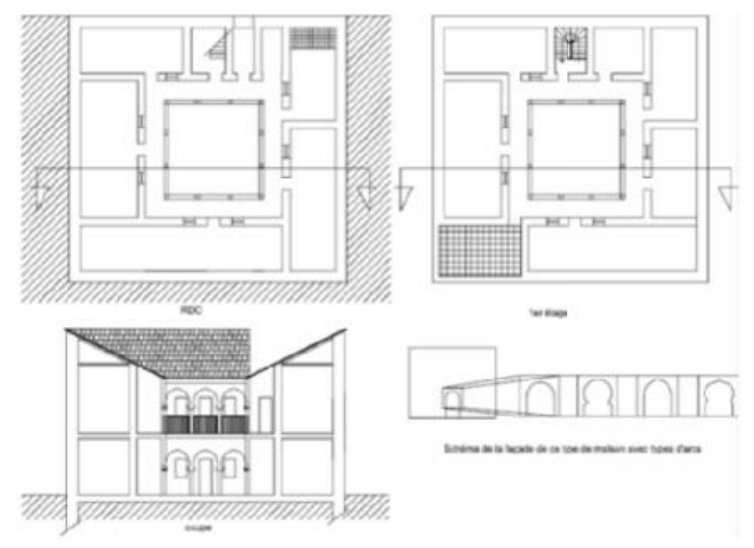

Figure 4. Example of Houses having first floor with peristyle (Source: Behiri, 2007)

\section{Houses Having First Floor With Peristyle}

This type of houses results from duplication of vertical type of traditional ground level houses with peristyle. The first floor usually occupies the entire level, but one of the adjoining corners is used as a terrace.

Either stairs leading to it stand from the patio, or they occupy a part of the gallery or in the same side as the main entrance and technical spaces. The "wast al-dar" is surrounded by four galleries, most often with broken horseshoe arches supported by columns with dual drum body (octagonal bottom and coil top). The front of this house type is the same as the previous type.

\section{Construction Technic Used in Cherchell's Islamic Heritage Houses}

The construction technics used in this heritage houses is the rammed earth (Pisé) bearing walls. "The pisé is a process by which the houses are built with earth, without support by any piece of wood, and without mixture of straw. It is an earth prepared for this purpose beat, layer by layer, between wood boards. Thus beaten it is bind; it takes more consistency, and form a homogeneous mass which can be raised at any height used for Homes" [3].

The Pisé used in the studied examples is a variety of the one used around the Mediterranean sea with some specific modifications. Before presenting these specificities, we will start by studying the rammed earth in its global geographical context: the Mediterranean region.

\section{The Rammed Earth Around the Mediterranean Region}

There are many variants of rammed earth technics, both in Algeria and in other countries where this building process is used since centuries. However, in all these variety, we always have the same principle (casing, ramming the earth). The difference comes down to the materials, other than earth sand and lime, added to the rammed mixture or in the general scheme of the wall. The aim of these additions is to strength the walls or to increase the construction speed and performance. It also due to problems of adhesion of coatings on the adobe walls. We thus find several variations in the Mediterranean countries such as:

- The application of lime mortars between the layers of earth or between the formwork in some countries such as France or Spain. This technic aims to protect the wall against erosion [4] or to protect the edges of the wall's formwork before laying the upper one [5].

- The introduction of flat stones or tiles on each layer of earth on the outside faces of the wall is used in France, in order to improve the grip of the coating [5].

- In Spain, several variants are used: introduction of stone, clay brick or increased proportions of lime in the mixture. Thus, stone and brick are added either in the soil mix, arranged in regular courses or chained on the corners [6]. The proportion of lime in the earth mix in some buildings reaches the third of the volume, which increases the resistance of structures but also their cost, this type is called "Real Tappial" or royal rammed-earth [7].

- In Portugal, stones shale layers, adobe bricks or flat tiles on lime mortar reinforce the layers of earth where its quality is poor for construction [8].

\section{The Rammed Earth in Algeria}

In Algeria, the rammed earth buildings date back to several centuries, both in urban centres and in the villages, from the coast to the hills and mountains. Today we find this practice mainly in the old building and it has almost disappeared from contemporary art of building (except a few old builders who continue to use it, there are no more new artisans who are acquainted with it).

The study of MEDA-Corpus [9] on rammed earth constructions in Algeria gives us some information about the different aspects of this construction method such as: 
- Thickness of foundations that varies between 80 and $120 \mathrm{~cm}$;

- The soil is mixed with broken tiles, bricks, pebbles, straw, and lime blocks;

- $\quad$ The height of the formwork can reach $150 \mathrm{~cm}$;

- The walls have a thickness that varies between 80 and $120 \mathrm{~cm}$.

\section{Rammed Earth Varieties Used in Cherchell Houses}

The structure of traditional houses in Cherchell consists mainly of bearing pisé walls (we also find stone walls in some houses). Two varieties of rammed earth are used in Cherchell's residential buildings [10], based on the rammed earth technic we presented above and were adapted to local conditions (available materials, climate, cost of construction, skills).

This is the most current one in Cherchell's buildings. The substructure of this type of wall is made of freestone (probably recovered from Roman remains found on site) or natural stones, the interstices are filled with broken bricks and tiles. The height of this substructure varies between 50 $\mathrm{cm}$ and $110 \mathrm{~cm}$.

The wall faces is composed with alternated bricks and mortar of lime, sand and gravel. Bricks vary in size, however their aspects (colour and thickness) are similar to those existing at the ancient monuments of the city, and they have been recovered from archaeological sites of Caesarea. The difference in the length and width of the bricks is certainly due to the cut of ancient bricks in two or three parts to save materials [10]. The bricks are laid alternately with a mortar layer with $10-15 \mathrm{~cm}$ thickness in order to have a finished external appearance of wall. A wall section shows that the bricks are only on its faces. These walls are composed of a mixture of earth, stones of various diameters, gravel, broken tiles and bricks and sometimes small pieces of lime.

The formwork of these walls are wooden of 70 to $80 \mathrm{~cm}$ height and $200 \mathrm{~cm}$ long (see fig. 5 and 6). The presence of terracotta fragment could be explained by the abundance in the soil of broken ceramic objects dating from ancient times, everywhere in the city [11]; these elements, with the addition of lime, also increase the resistance of the used earth.

In some cases, chaining at the corners is made of stone recovered from roman monuments [11].

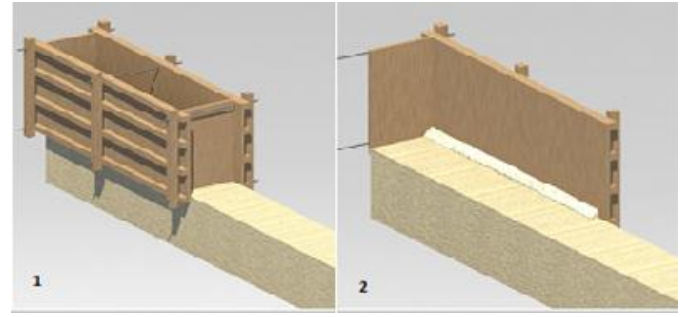

Figure 5. Construction stages of rammed earth wall lift with the face of alterning bricks and lime mortar (Source: Alliche S., 2012)

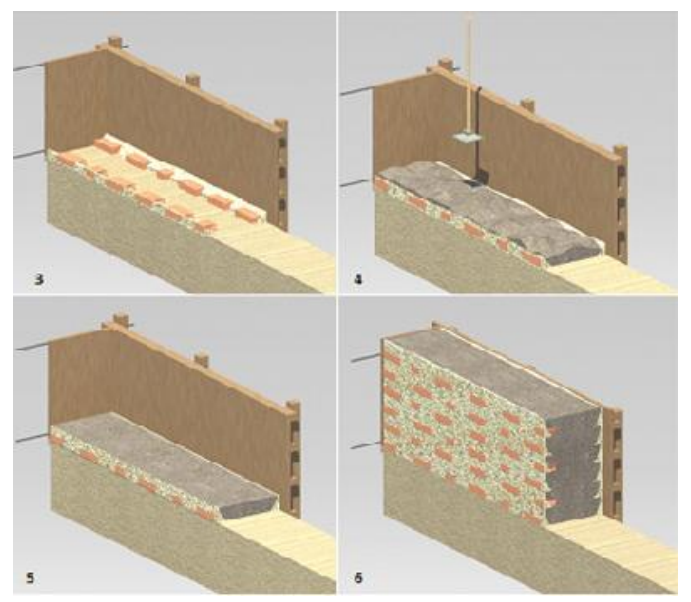

Figure 6. Construction stages of rammed earth wall lift with the face of alterning bricks and lime mortar (Source: Alliche S., 2012)

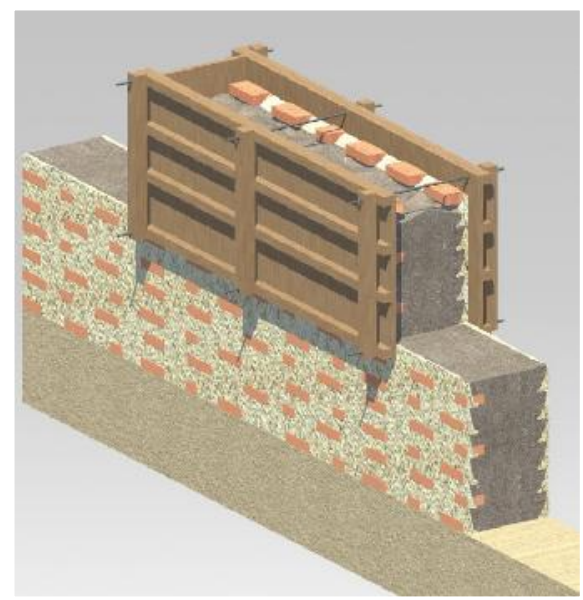

Figure 7. Construction stages of rammed earth wall lift with the face of alterning bricks and lime mortar (Source: Alliche S., 2012)

\section{Variant Two}

It is rammed earth walls with lime mortar layers in wall sides. They are easily recognizable by the attachment of the coating on mortar layers, which traces parallel horizontal lines on the wall. 
To study this kind of walls and identify their size and components, we used a square geometric frame with $10 \mathrm{~cm}$ side (see fig. 7 and 8 ) on decrepit walls.

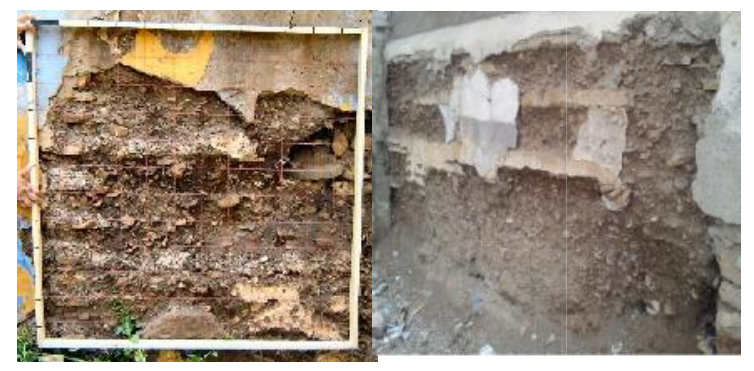

Figure 8 and 9. Study of two sample walls (Source: Behiri 2007)

These are mainly domestic or inside walls, not exposed to water and erosion. Thus, the stone base of such walls is less high than the previous model (protection against erosion is not required).

The mortar is made of lime, sand, soil and gravel. The rammed earth is composed by, as for variant one, gravel, small broken pottery, lime and, sometimes, animal bones (see fig. 7 and 8). The angles of such walls are reinforced with several mortar layers.

The use of mortar joints on siding could be explained by reasons of coatings attachment because they are difficult to apply on earth walls especially if they are sandy.

\section{Architectural Language: Cherchell's Arch in Cherchell's Islamic Heritage Houses}

In terms of architectural language, Cherchell's Islamic residential buildings is austere (like the majority of Islamic architecture), without any decorative elements, especially outside.

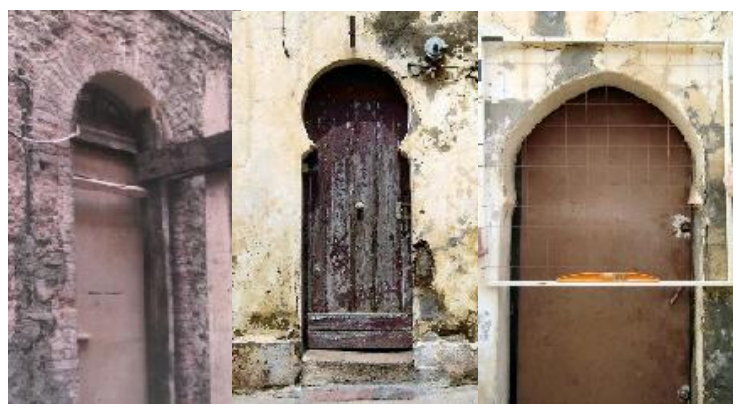

Figure 10. Identified arches in Cherchell's Islamic houses (Source: Behiri, 2007)
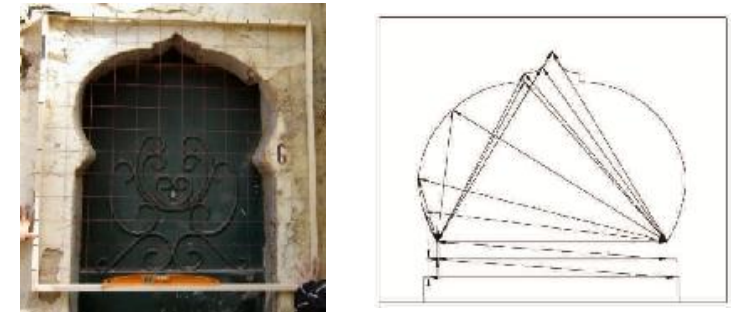

Figure 11. A Cherchell's arch situated on the front door of a listed house (cultural heritage). (The frame survey is on the left and the triangulated survey on the right)

(Source: Behiri, 2007)

In our study, the only decorative element that we found at the front are the arches in different variants (mainly upper the front doors) with three known ones: semi-circular arch, horseshoe arch and broken arch. The fourth variety that was special (we called it Cherchell's arch) is based on basket handle shape that ends with a triangular accolade [11].

We conducted surveys of arches in these houses, using two different methods: square geometric frame with $10 \mathrm{~cm}$ side (see fig. 10), and a triangulated metric survey. This allowed us to confirm its specificity through its geometric and constructive layout.

Before confirming its originality, we studied the different arch's types in Islamic architecture and around the Mediterranean Sea through history. We established then a summarised table locating and dating the arches' geographical spreading in this area.

Geometrically, this arch is based on a semicircular arc divided into two vertically in order to introduce the accolade in this space (see fig. 9) then it is overstepped with two new centres [11]. The upper part of the arc curve has two centres (01 and 02) that are on the same horizontal line; both centres are separated by a distance equivalent to the opening of the brace [11]. Both sides of the bottom part have two centres, which are situated on the diameter of the arch with an opening compass equivalent to $1 / 5$ th of $D$ ( $D$ is the diameter of the arch). The opening of the brace is $1 / 5$ th of the opening of the arch (see fig. 11) [11].

This arc is inserted within rammed earth walls and forms the shape of the openings. It is made of terracotta bricks of the following dimensions: a length varying between 21 and $22 \mathrm{~cm}$, a width of 10 to $10.5 \mathrm{~cm}$ and a height of 4 to $4.8 \mathrm{~cm}$, interconnected with a mortar of lime and sand with a gap that varies between $0.5 \mathrm{~cm}$ and $1 \mathrm{~cm}$ at the inner side of the arch and between $3 \mathrm{~cm}$ and $3.5 \mathrm{~cm}$ at the rear line of bricks. 

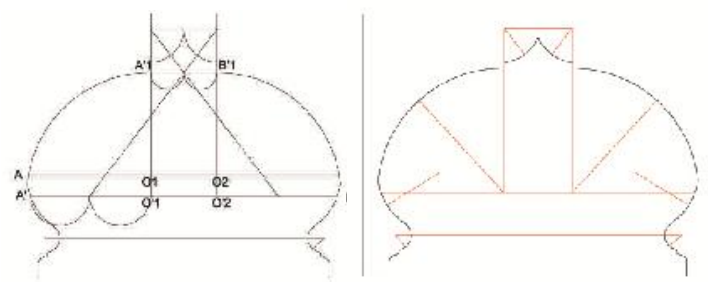

Figure 12. Geometrical layout of Cherchell's Arch (Source: Behiri, 2007)

The bricks are arranged horizontally with an offset to match the accurate shape (using a template) and following a radiating plane whose centre points are on the diameter of the arch. At the accolade, bricks are shifted up by the same distance as the shift of the accolade (using a removable formwork with two curved portions and a wire), with at the level of the key; a cut in the bricks to have the shape of the accolade using mortar [11].

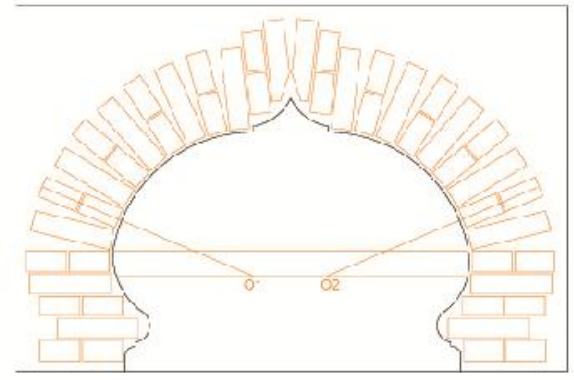

Figure 13. Construction method of Cherchell's arch (Source: Behiri, 2007)

The bricks are arranged in two layers to pass through the thickness of the opening of $24,5 \mathrm{~cm}$, and in an alternative way: once horizontally and the other vertically (see fig. 12). The shape of the finished arch is given up by a lime mortar, sand and earth.

\section{Conclusion}

The traditional Cherchell's houses architecture is a kind of Mediterranean Islamic heritage housing architecture adapted to its environment (social, natural, economic). It is based on the scheme of the introverted building, organized around a central courtyard "a patio" for climate reasons (to have a shaded outside living space) and social reasons (to respect family life privacy).

These houses are built using a natural sustainable material: the rammed earth. The rammed earth in Cherchell's buildings is modified in order to make it more resistant and cheaper by the introduction of recovered materials from the roman ruins (bricks, tiles and stones): in the substructure (to prevent moisture rising), on the wall faces (to prevent erosion), and in the rammed earth (to strength it). These solutions show us that the ancient builders acquired and developed a specific know-how that solves their construction problems and matches their culture. It has also specific arches based on the basket handle horseshoe arches.

Cherchell's arch is built on the same principle as the semi-circular overruled arch, however, geometric changes were made to it and a brace was added, giving it its unique appearance.

Our study demonstrated that Cherchell contributed to the evolution of arches, adding a new element in the common usual arc directory already known by specialists.

\section{References}

[1] Leveau Ph. Caesarea de Maurétanie: une ville romaine et ses compagnes. French School in Rome, Palazzo Farnese, p. 77, 1984.

[2] Behiri A. Heritage Rehabilitation in Sustainable Development Policy for a Better Environment Quality in Small Historical Coastal Cities: the Case of Cherchell in Algeria. Procedia Engineering, Vol. 21, pp. 753-759, 2011.

[3] M. Patel. Doat P. Wind and Solar Power Systems. CR[1] Construire en terre. Alternatives et parallèle. CRATerre, France, p. 13, 1979.

[4] Pignal B. Terre crue, techniques de construction et de restauration. Eyrolles, Paris, France, p. 34, 2005.

[5] De Chazelles C. A. Guyonnet F. La construction en pisé du LanguedocRoussillon et de la Provence, du moyen-âge à l'époque moderne. In proceeding of Echanges transdisciplinaires sur les constructions en terre crue. Villefontaine (Isère), France. May, 2005.

[6] Graciani Garcia A., Tabales Rodriguez M.A. El tapial en el area sevillana. Avance cronotipologico estructural. In Arqueologia de la arquitectura, vol. 5, pp. 135-158, january-december, 2008.

[7] Jaquin P., Augrade C., Gerrrard C. Historic rammed earth structures in spain, construction technique and a preliminary 
classification. Proceeding of the international symposium on earthen structures, Bangalore, India, August 22-24, 2007.

[8] Correia M. Tecnicas portuguesas de construçao em terra : a taipa alentijana. In proceeding of Seminário de Arquitectura de Terra em Portugal: Divulgação, Investigação. Contemporaneidade e Formação, Lisbon, Portugal. october, 2003.

[9] http://www.medacorpus.net/eng/index.asp
[10] Alliche, S. \& Chennaoui, Y. The formalization as an identification process of a constructive way: the rammed earth of Cherchell (Algeria). Rammed Earth Conservation Editors Mileto. C, Vegas. F \& Cristini. V, CRC Press/ Balkema, Taylor \& Francis Group, Londres, pp.47-52, 2012.C Press, 2012.

[11] Behiri A. La formalisation comme processus révélant le système constructif d'un élément architectural: Cas de l'arc cherchellois. EPAU, Algiers, Algeria, p. 126, 2007 